\title{
A UNIVERSIDADE QUE ESCUTA E COMPARTILHA: VIVENCIANDO EXPERIÊNCIAS DE POLÍTICAS DE INCLUSÃO NA AMÉRICA LATINA
}

\author{
Ana Lúcia Oliveira Aguiar ${ }^{1}$ \\ Rosilene da Costa Bezerra Ramos ${ }^{2}$ \\ Francisco Mayccon Passos Costa ${ }^{3}$
}

\begin{abstract}
RESUMO
Este projeto nasce da experiência prática das aç̃̃es da política de inclusãopensadas pela Diretoria de Políticas e Ações Inclusivas (DAIN), da Universidade do Estado do Rio Grande do Norte, na América Latinae, para este estudo, intitulado, A universidade que eu vivo é uma universidade que escuta e compartilha: vivenciando experiências de Políticas de Inclusão na América Latina. Propõe uma temática diversificada voltada para o compartilhamento e troca de experiências, com vistas à implantação de uma rede interuniversitária para a criaçãoe implementação de ações tendo como base a promoção do respeitoaos princípios da diversidade humana e a efetivação de direitos para acultura da paz. Utilizaremos como metodologia as narrativas reflexivas autobiográficas de formação com base nos estudos de Josso (2010) e no princípio da aprendizagem formativa ao longo da vida de Freire (2005). Resulta em discussão de formação docente, práticas e trajetóriaseducativas, no cotidiano de territórios como espaços de pluralidades culturais perseguindo o afloramento do (re)encantamento da arte dasvivências educativas, das solidariedades que empurram os sujeitos para a reciprocidade, para as trocas, pelo gosto da busca pelo Outro,pela reconstrução das identidades, pelo entendimento da memória enquanto movimento, função e construção social e manutenção de vínculos. O envolvimento, partilha e práticas de formação, nas regiõesde fronteira entre os plurais espaços de aprendizado, nas diversas áreas de conhecimento no âmbito internacional, são base para o reconhecimento dos diferentes sujeitos em sua diversidade, capazes de dialogar, de compartilhar vínculos ancorados em seus lugares de pertença.
\end{abstract}

Palavras-Chave: Território de Formação. Experiências. Pluralidades Culturais. Reciprocidades.

\section{THE UNIVERSITY THAT LISTENS AND SHARES: EXPERIENCINGINCLUSION POLICY EXPERIENCES IN LATIN AMERICA}

\footnotetext{
1 Doutorado em Sociologia pela Universidade Federal da Paraíba (UFPB) e Pós-Doutoranda do Programa de Pós-Graduação em Educação da Universidade Federal do Ceará (UFC). Professora da Faculdade de Educação da Universidade do Estado do Rio Grande do Norte. E-mail: anaaguiar@uern.br.

2 Mestra do Programa de Pós-graduação em Educação (POSEDUC/UERN). Especialista em Educaçãopela Universidade do Estado do Rio Grande do Norte (UERN) e Especialista em Atendimento Especializado na Perspectiva pela Educação Inclusiva pela Universidade Estadual Paulista Júlio de Mesquita (UNESP).E-mail: rosilenerb@hotmail.com.

3 Mestre em Educação pela Universidade Estadual do Rio Grande do Norte (UERN). Professor do curso de Psicologia da Faculdade Católica do Rio Grande do Norte (FCRN). Psicólogo da Diretoria dePolíticas e Ações Inclusivas (DAIN), da Universidade do Estado do Rio Grande do Norte (UERN). E-mail:mayccon@yahoo.com.br.
} 
ABSTRACT

This project is born from the practical experience of inclusion policy actions designed by the Directorate for Inclusive Policies and Actions (DAIN), of the State University of Rio Grande do Norte, in Latin America and, for this study, entitled, The university I livein is a university that listens and shares: experiencing experiences of Inclusion Policiesin Latin America. It proposes a diversified theme aimed at sharing and exchanging experiences, with a view to implementing an inter-university network for the creation and implementation of actions based on the promotion of respect for the principles of human diversity and the realization of rights for the culture of peace. We will use as a methodology the reflective autobiographical narratives of training based on the studiesof Josso (2010) and the principle of formative learning throughout Freire's life (2005). It results in the discussion of teacher training, educational practices and trajectories, inthe daily life of territories as spaces of cultural pluralities pursuing the outbreak of the (re) enchantment of the art of educational experiences, of the solidarities that push the subjects towards reciprocity, for exchanges, through I like the search for the Other, forthe reconstruction of identities, for the understanding of memory as movement, function and social construction and maintenance of bonds. The involvement, sharing and trainingpractices, in the border regions between the plural spaces of learning, in the various areas of knowledge at the international level, are the basis for the recognition of the different subjects in their diversity, capable of dialogue, of sharing bonds anchored in their places of belonging.

Keywords: Formation Territory. Experiences. Cultural Pluralities. Reciprocities.

\section{INTRODUÇÃO}

Este projeto nasce da experiência prática das ações da política de inclusão pensadas pela Diretoria de Políticas e Ações Inclusivas (DAIN), da Universidade do Estado do Rio Grande do Norte (UERN) com base no Plano Estratégico de Ação, período 2013/2021, em andamento na América Latina e, para este estudo, intitulado, A universidade queeu vivo é uma universidade que escuta e compartilha: vivenciando experiências de Políticas de Inclusão na América Latina. Somamos a parceira com Programa dePósGraduação em Educação (POSEDUC/FE/UERN) e a Faculdade Católica do Rio Grande do Norte (FCRN). Trata-se de um projeto que reúne universidades públicas e privadas no âmbito nacional e internacional concretizados, até o momento, os seguintes países: Brasil, Argentina, Cuba, México, Chile, Perú, Colômbia. Propõe uma temática diversificada para a Formação Continuada realizada com estudantes da pósgraduação e técnicos especializados da DAIN, especialistas, mestres e doutores para o compartilhamento e troca de experiências, com vistas à implantação de uma rede interuniversitária para a criação e efetivação de ações tendo como base a promoção do respeito aos princípios da diversidade humana e a efetivação de direitos para a cultura da paz.

Tendo como central a política de aproximação entre os referidos países, palestras, conferências, programação para formação continuada, rodas de conversa, atividades de campo em comunidades locais, relatos (auto) biográficos, narrativas reflexivas de formação. Tem, nos estudos de Josso (2010) e no princípio da aprendizagem formativa ao longo da vida de Freire (2005) sua base conceitual e metodológica. Resulta em discussão de formação docente, práticas e trajetórias educativas, no cotidiano de territórios como espaços de pluralidades culturais perseguindo o afloramento do (re) encantamento da arte das vivências educativas, das solidariedades que empurram os sujeitos para a reciprocidade, para as trocas, pelo gosto da busca pelo Outro, pela reconstrução das identidades, pelo entendimento da memória enquanto movimento, função e construção social e manutenção de vínculos.

Composto por técnicos especializados da DAIN, por mestrandos do Programa de Pós-Graduação em Educação da UERN, professores e gestores da Faculdade Católica do Rio Grande do Norte, por professores e gestores das instituições parceiras 
da UERN, situadas no contexto da cidade de Mossoró/RN, cujo trabalho está voltado para as políticas de inclusão para pessoas com deficiência, este projeto, de 2013 a 2019, se desenvolveu, nos países da América Latina, acima anunciados.

O envolvimento, a partilha e as práticas de formação, nas regiões de fronteira entre os plurais espaços de aprendizado, nas diversas áreas de conhecimento no âmbito internacional, são centrais para o reconhecendo dos diferentes sujeitos em sua diversidade, capazes de dialogar, de compartilhar vínculos ancorados em seus lugares de pertença.

Cabe ressaltar que de 2013 a 2019 este Projeto de Formação Continuada realizou suas atividades de forma presencial com o deslocamento da equipe executora aos países acima listados. Salientamos que em 2013 o referido projeto fez sua primeira incursão na Europa, em Portugal, promovido pela Associação de Docentes de Educação com sede na cidade de Almada por ocasião do III Congresso Internacional de Inclusão e Equidade.

Por seu turno, no ano de 2020, com a Pandemia da COVID-19 as atividades foram realizadas na modalidade remota síncrona. Reunimos oito palestrantes dos países vizinhos com presença do Chile, da Colômbia, da Argentina, da Bolívia, do Peru quando da realização do VIII Seminário de Narrativas (auto) biográficas - Quero voltar a te ver. Essa experiência será relatada ainda neste espaço de produção.

Este projeto de Formação Continuada Internacional desdobra-se nas reflexões com destino à (re) significação no viés da quebra de barreiras historicamente construídas, atitudinais, físicas, procedimentais, conceituais para a superação de preconceitos em seus convívios, atuações, dimensões de vida. Confirmamos sobre a importância das narrativas (auto) biografia como prática reflexiva para a (re) significação da formação, pois a partir das narrativas de histórias de vida nos autoformamos e nos autotransformamos. Permite o exercício do conhecer-se e vivenciar a abertura para a alteridade, tendo como pista a aproximação, o conhecer, o conviver, o desaprender sobre o que nos impede para abrir um caminho interminável de conhecimentos culturais dentro da diversidade. A Internacionalização/Inserção Internacional, levadas a efeito pelo projeto A universidade que eu vivo é uma universidade que escuta e compartilha: vivenciando experiências de Políticas de Inclusão na América Latina é uma ação destinada à participação em Eventos Científicos na América Latina. AAção de Mobilidade Internacional com outros Programas e Centros de Pesquisa e Desenvolvimento Profissional se faz com o estabelecimento de intercâmbios de cooperação com outras instituições educacionais em nível local, regional, nacional e internacional, com contribuições no compartilhamento de pesquisas e trocas de experiência.

\section{A INTERNACIONALIZAÇÃO DAS POLÍTICAS DE INCLUSÃO IMPLICA EM SUPERAR IMPEDIMENTOS E BARREIRAS}

As ações levadas a termo por este projeto intitulado A Universidade que eu vivo é uma universidade que escuta e compartilha: vivenciar experiências de Políticas de Inclusão na América Latina pensado pela Diretora de Políticas e Ações Inclusivas (DAIN), na soma com o Programa de Pós-Graduação em Educação, da Universidade do Estado do Rio Grande do Norte, implementam uma feitura mediada pelos ensinamentos freireanos de que educar implica em superar todas as formas de exclusão que, na perspectiva da Formação Continuada, sustentada neste projeto de internacionalização das políticas de inclusão, tem a palavra geradora central para o processo de ação, reflexão e ação, estudo, leitura e escrita, com vistas ao conhecimento de si, do outro e do mundo do outro.

A referida ação fundamenta-se na busca pela Formação Continuada, pela implicação 
com o exercício da autonomia e independência das pessoas em seu universo simbólico pela troca de experiências e compartilhamento do seu saber/fazer, motivados pela partilha de ações no mote da Educação para a Diversidade e Inclusão. Trata-se de um momento que pretende aproximar profissionais de várias áreas do conhecimento, e de vários países, tendo como base sua legislação específica, protocolos nacionais e internacionais para a promoção da alfabetização dos sentidos que busquem a consolidação do respeito aos princípios da diversidade humana inclusão das pessoas com deficiência e organize uma rede fortalecida pelo entendimento da pertinência da perspectiva de inclusão no âmbito dos povos no/do mundo.

Resulta da compreensão de que é preciso a viabilização de ações e políticas voltadas para a acessibilidade e efetivação de direitos entre as universidades nacionais e internacionais, públicas e privadas, instigando a construção das dimensões da vida dos sujeitos para a (re) significação de sua forma de ser e conceber suas potencialidades, suas humanidades. As políticas de Internacionalização Inserção Internacional implicam uma ação de disposição conjunta entre Países, a saber, cooperação científica interuniversitária através da articulação entre o ensino, a pesquisa e a extensão de forma conjunta entre os países na mira da consolidação de intercâmbios de estudantes, professores e técnicos. Busca Programas de Formação - recursos humanos locais: apoio de visitas de média ou longa duração de professores estrangeiros convidados por cursos de doutorado de instituições de Ensino superior (IES) brasileiras; apoio à inserção acadêmica de professores brasileiros em renomadas instituições de ensino superior no exterior (para ministrar aulas, desenvolver pesquisas e desenvolver atividades de orientação técnica e científica). Essa modalidade de programa incrementa as relações bilaterais no meio acadêmico e a divulgação da ciência, tecnologia e cultura brasileiras entre os países envolvidos.

Todas essas reflexões trazem impactos da internacionalização da educação superior na docência universitária e a perspectiva da construção da cidadania global por meio de ações globalizadas. De acordo com Morosini e Ǔstárroz (2016, p. 35) "A internacionalização da educação tem sido um dos mais importantes fatores de impacto da educação superior e, especificamente, da docência universitária". É fato que embora inerente à instituição universitária e tradicionalmente acolhida na função pesquisa, a partir deste século, no bojo da sociedade do conhecimento e da globalização, a internacionalização se direciona para a função ensino e para todo seu arcabouço constitutivo, apontam os referidos autores. Temos certeza de que nos plurais espaços de convívio e nas diferentes dimensões das políticas a construção da cidadania global repercute na condição de vida das pessoas de forma qualitativa para a produção da vida.

Implica em ações com olhar para si e para a diversidade e a inclusão, com vistas às políticas públicas considerando a responsabilidade da academia com sua prática para além dos muros da universidade, ganhando a dimensão do rompimento de fronteiras, e para bem próximo daqueles que são estigmatizados muitas vezes por tempos a fio. Implica na formação de um olhar para a diversidade e para a inclusão de pessoas com deficiência, considerando o visível crescimento de participação de pessoas com deficiência nos seus diversos espaços de sociabilidade de educação, aspecto significativo e que vem aquecendo a quebra de barreiras atitudinais e enfrentamento ao capacitismo.

Ao reafirmar o compromisso social da universidade, em conjunto com outras universidades da América Latina como forma de inserção nas ações de promoção e garantia dos valores democráticos, de igualdade e desenvolvimento social, se coloca como instituição acadêmica que objetiva interligar a universidade, com seus vizinhos acadêmicos no mundo em suas atividades de ensino, pesquisa e extensão, com as demandas do dia a dia de cada um em seus lugares de sociabilidades. Sem dúvida o diálogo com a comunidade, nacional e internacional, o olhar atento para as barreiras 
construídas e as situações de impedimento da vida permitirão a troca e compartilhamento entre os saberes e fazeres, pois, provocarão a participação da comunidade acadêmica na construção de ações, com vistas ao respeito às diferenças.

O princípio do compromisso social e educacional é central na ação. Projeto social se constrói com a participação dos sujeitos, forjada pelos sujeitos com o mundo, na práxis como diz Freire (1996). A Universidade do Estado do Rio Grande do Norte cumpre seu papel social e compromisso com a formação continuada e formação de recursos humanos que se comprometam com outra leitura e resgate da dívida do longo tempo de exclusão de sujeitos submetidos ao silêncio. Implica ainda o imperativo de uma interpretação crítica da realizada, um olhar de estranhamento e de desnaturalização dos ambientes de modo a fomentar ações inclusivas, e, ao mesmo tempo, provocar novas necessidades para o desenvolvimento individual e coletivo. Essa missão encontra-se compatível às novas exigências sociais e educacionais de uma instituição de ensino superior e da proposta da educação para o século XXI.

Concordamos que "Não há mais sentido na formação de profissionais e cidadãos para inserção exclusivamente local, haja vista que, no contexto da globalização, as experiências contemporâneas - de vida e laborais - extrapolam os contornos locais" (WÄCHTER, 2000). Uma política de formação de profissionais dentro de uma lógica global permite desencadeamento de uma consciência de enfrentamentos dos desafios globais em rede, em colaboração. A universidade precisa insistir na construção de olhares plurais, exercitar várias lentes de qualificações internacionais e de laços interculturais que potencializem os sujeitos para a compreensão da multiculturalidade.

Diante de um novo modo de fazer educação, a informação, o conhecimento, a sensibilização para o outro, o aquecimento das energias para a superação e quebra de barreiras, a partir de todos e todas é fundamental. $O$ saber acadêmico, aliado ao olhar para o cotidiano, bem como para os espaços plurais de vida, no caso deste estudo, possibilitará a geração de singularidades que desembocam em novos modos de produzir, em ações concretas. É nesse espaço que deve se inserir as atividades dos docentes, discentes e técnicos através da institucionalização da inclusão universitária, na busca de contribuições que efetivamente conduzam à melhoria da qualidade de vida dos povos no mundo da produção da vida.

\section{MIRADAS APROXIMATIVAS - O DOM DA PALAVRA DA/NA EXPERIÊNCIA}

No cotidiano da vida entrelaçamos o aprender, a educação com a experiência (BONDIÁ, 2002; BRANDÃO, 1995). A produção da vida não está apenas na escola, mas na vida, no cotidiano da vida, nas miradas apreciativas sobre o outro. Aprendemos em todos os lugares e, em especial, nas dimensões do mundo. Por sua vez, Freire (2005) alerta que praticar os aprendizados pede abertura para o outro, sensibilidade, aproximações, afetividades, humanização. Ao mesmo tempo, lembramos sobre a experiência e como nos ensina Bondiá (2002, p. 21) "A experiência é o que nos passa,o que nos acontece, o que nos toca. Não o que se passa, não o que acontece, ou o que toca".

Para essa experência que é o que nos passa e o que nos acontece reunimos a dimensão da sensibilidade, com o esperançar no dom da palavra, do sujeito individual e coletivo, da emoção, da busca pelo outro, do praticar a criatividade e descoberta do outro, na capacidade do outro se movimentar para o outro, o acordar no outro e alertarse para a sua presença no entendimento do que será sempre inacabado. As lições do corpo que busca a certeza na incerteza indo, atravessando fronteira e, em especial, as fronteiras do coração, o som do coração. A experiência no encontro com o outro na habilidade do corpo se relacionar, aprender, desaprender. 
No percurso da experiência do projeto A Universidade que eu vivo é uma universidade que escuta e compartilha: vivenciar experiências de Políticas de Inclusão na América Latina construímos lugares, como afirma Mauss (1974) onde saltam experiências e vivências onde o apreciar é o ponto primordial. Reafirmamonos sobre os atalhos, veredas e rincões, nesses lugares abertos às oportunidades.

É o que habilita e valida nossas incursões pela América Latina e o que continuará nos instigando. Lugares carregados de emoção e do possível para aquecer nosso pensar, nossas reflexões, nossos compartilhamentos. Produzimos esses lugares de memória, memória afetiva, memória reminiscência, memória que desperta memórias com miradas apreciativas entendendo nossos outros da América Latina como memórias de vida construídas na relação social entre pesquisador e informante (MENEZES, 2004).

Brandão (1995) e Freire (2005) nos alertam para uma educação sem marcas de uma educação tradicional, racional. Compreendemos que conduzir a universidade, suas lições, seus sujeitos da prática significa sentido e respeito a uma aprendizagem carregada de sentimentos de humanização, posto que se veem desterritorializadas.

Aprendemos com Brandão (1995), que ninguém escapa à educação e que em casa, na rua, na escola, na universidade, de uma forma ou de outra, juntamos laços de vida. Tardif (1996) ressalta que os saberes são diversos, e que dialogam com os saberes da experiência, uma vez que, têm como âncora o dia a dia e o autoconhecimento e, contextos e região de fronteira entre os saberes em seus mais diferentes espaços culturais.

A palavra é a doação da doação. É a dádiva das dádivas diz Caillé (2002). É o que transborda. É o que abunda. A palavra carrega emoção e possibilidade de fazeres da emoção. Na experiência está a paixão (BONDIÁ, 2002). O referido autor pensa sobre o que nos acontece, o que nos toca e a experiência como um território de passagem. Assim sendo, diz Bondiá (2020) a experiência é uma paixão. O sentido da experiência, por esse olhar, é o sentido da paixão, pois se anima no sentimento e este não poderá alimentar como ação, mas como o sujeito do sentido, das possibilidades, da afetividade.

Pois bem, o que foi realizado, até o momento, durante os dias de vivência pelas universidades, pelas ruas, pelas comunidades, pelos arrabaldes, pelas veredas e atalhos das cidades de Santiago (Chile) Cordoba e Buenos Aires (Argentina), Havana e Cienfuergos (cuba), Cidade do México (México), Lima (Peru), Medellin (Colômbia), foi exatamente essa busca, essa procura, foram esses encontros. A paixão na experiência, que nos passa, o que nos acontece. E, repentinamente, uma surpresa. Onde não imaginávamos, quando nem pensávamos, alargavam-se os encontros. A cada espaço das universidades visitadas, de acordo com a Programação deste Projeto pessoas aproximavam-se na doação da palavra transbordante.

Apontamos atividades realizadas com base no Projeto $A$ universidade que eu vivo é uma universidade que escuta e compartilha: vivenciando experiênciasde Políticas de Inclusão na América Latina, projeto que discute sobre o estatutodo outro, em seus processos de (auto) formação e práticas educativas centradasna pluralidade e consciência da diversidade humana na pesquisa e na formação de sujeitos em espaços educativos. As pesquisas vinculadas ao referido projeto perfazem a produção histórica da cultura, as (auto) biografias, as identidades e memórias, a educação especial/inclusiva e o lugar da diversidade como espaços de produção de saberes e práticas em espaços formais, e não formais, com ensejo à inclusão no espaço escolar/acadêmico/comunidades/social.

Essa troca de experiências com os nossos outros, as vivências com a diversidade, o exercício para estabelecermos nossos elos, o conhecimento, direto, de situações e contextos circunvizinhos, fazem parte do cotidiano das práticas educativas entendendoas com centralidade nas miradas aproximativas. Dos lugares escolares e não escolares, dos cadernos de classe, das lições do dia a dia, dos livros, dos artigos, dos eventos 
acadêmicos, das discussões nos grupos de pesquisa como das ruas, dos logradouros, das praças, dos arrabaldes, da circunvizinhança retiramos o alimento e, certamente, nos dão cabimento para tal vontade de proposta.

Este projeto aloja a discussão de formação docente, práticas pedagógicas e trajetórias educativas, no cotidiano das instituições formais e não formais, perseguindo o afloramento do (re)encantamento da arte das vivências educativas, das solidariedades que empurram os sujeitos para a reciprocidade, para as trocas, pelo gosto da busca pelo Outro, pela reconstrução das identidades, pelo entendimento da memória enquanto movimento, função e construção social, pela prática de formação e pesquisa em espaços (auto) biográficos, pela manutenção dos vínculos. Nesses territórios do lugar do outro nos países visitados, até o momento, da noção de formação como objeto cultural, do saber, do aprender, do fazer, residem pertinentes forças de investimento para a formação de humanidades mediadas pela recombinação dos seus sentidos.

Assim argumentando, este projeto advoga o envolvimento de formação e práticas de formação, nas regiões de fronteira entre os plurais espaços de ensino, de pesquisa e de extensão, nas diversas áreas de conhecimento. A educação como bem simbólico, nos contextos formais e informais, reconhecendo os diferentes sujeitos em sua diversidade e capazes de dialogar, de compartilhar vínculos ancorados em suas pertenças e transpostos para a sociedade, como um todo, em seu diálogo com a dimensão da autonomia que remete à relação dos sujeitos com o Outro. A essas se ressalta as políticas voltadas para a Educação Especial, como Diversidade e Inclusão, na perspectiva do respeito aos princípios da diversidade humana, para as quais os órgãos governamentais e a sociedade civil como um todo, forçados pela pressão exercida, começam a refletir outras formas de pensar o social ao perceber muitas redes sendo criadas de apoio à pessoas com deficiência, a despeito ainda de uma carga forte de competição, de lógica de mercado, de qualidade, expressa em números, da eficiência como sinônimo de hegemônico.

Este Projeto desdobra-se, cabe repisar, nas reflexões com destino à (re) significação da escolaridade e a perspectiva da quebra de barreiras historicamente construídas, atitudinais, físicas, procedimentais, conceituais para a superação de capacitismo, de preconceitos em seus convívios, atuações, dimensões de vida. Confirmamos sobre a importância das narrativas (auto) biografia, levadas à efeito em todos os países no raio deste projeto, como prática reflexiva para a (re) significação da formação, pois a partir das narrativas de histórias de vida nos autoformamos e nos autotransformamos. Permite o exercício do conhecer-se e vivenciar a abertura para a alteridade, tendo como pista a ascensão social pelos estudos dos referidos estudantes.

Somando aos estudos (auto) biográficos percebemos que o processo de vivências dos sujeitos em sociedade, o empoderamento, no limem, entendida como o lugar de aprendizados, nessa direção, aponta para uma forma de prática de vida que implica no exercício da desnaturalização de territórios, o cotidiano, que desbanaliza olhares preconceituosos sobre os sujeitos. Conduz à prática do estranhamento do/no cotidiano dos sujeitos, de modo que os leva a uma compreensão da realidade para além do imediato pela sua lucidez de ser e estar num mundo de diversas relações, conforme estudou Freire (1979). O homem, diz o autor, ao refletir sobre si mesmo, poderá descobrir-se como ser inacabado e, como tal, poderá ser sujeito da própria educação e não objeto dela. Sendo assim, a busca por mais educação deve ser embasada na humildade, quanto a sua interação com os seus semelhantes; interação essa que "comunica um saber relativo a outros que possuem outro saber relativo" (FREIRE, 1979).

Desses lugares, sujeitos e acontecimentos, por entre lugares deste projeto, memórias das dimensões de vida e atividades em contextos locais, em diálogo na região de fronteiras onde os países se tocam, onde as áreas do conhecimento se tocam, destacamos as ações do projeto A universidade que eu vivo é uma universidade que 
escuta e compartilha: vivenciando experiências de Políticas de Inclusão naAmérica Latina, promovido pela Diretoria de Políticas e Ações Inclusivas em parceriacom a Faculdade Católica do Rio Grande do Norte, coordenado pela Professora Dra.Ana Lúcia Oliveira Aguiar e tecido, a muitas mãos, com estudantes, professores e técnicos de ambas as parcerias, como a argila nas mãos do oleiro sob um mosaico de alteridade.

Inicia-se o percurso apreciativo em 2013, com destino a Almada/Portugal momento em que levamos os entrelaçamentos de um trabalho erguido de partilhas inclusivas em rede de solidariedade. Coube ao seu título os saberes de uma Memória da dimensão (auto) formativa na esteira da construção de um trabalho de conclusão de curso com surdo apresentado durante o III Congresso Internacional de Inclusão e Equidade, 2013, Almada/Portugal. III Congresso Internacional de Inclusão e Equidade. Almada promovido pela Pró-Inclusão - Associação de Docentes de Educação Especial. Conhecemos nossos outros de vários países que para Almada se dirigiram com apetite de compartilhar, partilhar, conhecer, apreciar.

Por sua vez, em 2014, preenchido pelo sonho de concretizar mais um projeto construímos o trabalho carregado de História, Memórias e Fuentes Orales, apresentado na cidade de Córdoba, durante o IX Encontro Internacional do Fórum Paulo Freire. Com a participação de cinco alunos (as) do Programa de Pós-Graduação da Universidade do Estado do Rio Grande do Norte. Um percurso envolvendo seis estudantes.

Para 2015, o rumo foi Buenos Aires/Argentina. Preparamos estudos com meta ao tema Prácticas docentes para el siglo XXI, na participação do IX Encontro Internacional 'Presencia de Paulo Freire. Com a participação de cinco alunos (as) do Programa de Pós-Graduação da Universidade do Estado do Rio Grande do Norte.

Os caminhos seguiam, no ano de 2016, para Cuba, cidades de Havana e de Cienfuegos a contribuir para o estudo das dificuldades envolvidas na produção do conhecimento na área de Educação, buscando alternativas para questões centrais relacionadas com o ensino (educação formal), mas também para iniciativas não formais e informais de formação humana. Caber ressaltar a relação de compartilhamento com a Universidade de Cienfuegos em Cuba, cujo coordenador do Programa de PósGraduação em Educação apresentou as possibilidades de convênio entre os países que lá estavam e Cuba no sentido de estreitar as relações internacionais.

Ao México seguimos em 2017 com trabalhos apresentados à Associação Mexicana de História Oral, com a participação no XI Congresso Internacional de História Oral na Cidade do México. Participamos com apresentação de Comunicação Oral no referido congresso. Atravessamos fronteiras para partilhas e narrativas sobre Histórias de Vida em desenhos: uma experiência de ensino e aprendizagem com idosos. O XI Congresso Internacional de História Oral: Paradigmas Y desafios de la Historia Oral: Nuevos temas y problemáticas del presente, abriu plurais reencantamos e estimulou o reaprender com o outro a partir dos variados projetos ensejado pelo XI Congresso Internacional de História Oral: Paradigmas Y desafios de la Historia Oral: Nuevos temas y problemáticas del presente. Abordagens levadas com foco na Formação de professores na perspectiva da aprendizagem da convivência pacífica inclusiva.

Em 2018 o Projeto A universidade que eu vivo é uma universidade que escuta e compartilha: vivenciando experiências de Políticas de Inclusão na América Latina, reafirma suas bases teóricas e práticas com destino a dois países. O primeiro foi o Peru, cidade de Lima e se instalam as atividades da de Formação Continuada com a Universidad Marcelino Champagnat ULMCH/Lima, tecendo os desejos de consolidações humanas com a I Jornada Pedagógica Internacional Brasil/Peru de Educação Inclusiva: práticas educativas, cultura, diversidade e inclusão.

No Chile, também, no ano de 2018 seria mais um dos países apreciados. Os projetos se intensificavam com desejos, escolhas e oportunidades agarradas com o coração, 
braços e abraços dos fazeres e sentires em diálogo e seus modos de praticar. A partir da Formação Continuada, supracitada cujo foco cativou as redes de solidariedade pela cultura da paz com os trabalhos da I Jornada Pedagógica Internacional Brasil/Chile de Educação Inclusiva: práticas educativas, cultura, diversidade e inclusão.

Com a rota traçada para a Colômbia em 2019 afiamos as emoções nos trabalhos dedicados à Universidad de Medellin na Formação Continuada com a I Jornada Pedagógica Internacional Brasil/Colômbia de Educação Inclusiva: práticas educativas, cultura, diversidade e inclusão. Traçados, retratos, portas, caminhos, vias e amálgama de dizeres pela via do corpo fala. Oficinas, palestras, encontros na universidade e nas cidades próximas com as quais a referida universidade realiza seus projetos de extensão.

Em 2020 experienciamos a primeira atividade do projeto $A$ universidade que eu vivo é uma universidade que escuta e compartilha: vivenciando experiências de Políticas de Inclusão na América Latina, na Modalidade Remota Síncrona realizadano período de 25 a 27 de novembro com a participação de 08 (oito) palestrantes dos países vizinhos com presença do Chile, da Colômbia, da Argentina, da Bolívia, do Peru quando da realização do VIII Seminário de Narrativas (auto) biográficas - Quero voltar a te ver.

Com uma Programação suave, aromática e permeada pelo dom da palavra, pela doação, pela generosidade do praticar tecemos plurais discussões na mirada sobre a cultura do outro que é nossa cultura também. Pensamos, discutimos e realizamos em lugares antes tão distantes, hoje tão próximos com apontamentos relacionados Legislação Brasileira para pessoas com deficiência - Acessibilidade e efetivação de direitos; políticas de inclusão para pessoas com deficiência no Estado do Rio Grande do Norte; Diretoria de Ações Inclusivas - Acesso e permanência de estudantes com deficiência no Ensino Superior; Políticas de Inclusão para alunos com deficiência no Colégio Diocesano Santa Luzia de Mossoró; Aplicação da Convenção sobre os direitos das pessoas com deficiência - inclusão no trabalho; Formação e Atendimento Educacional Especializado (AEE)/Brasil; Transtorno do Espectro Autista (TEA): reflexões sobre narrativas de inclusão de estudantes autistas para a superação de barreiras; Educação de surdos no Brasil: desafios e avanços; Centro de formação de educadores e atendimento ao surdo de Mossoró (CAS); Desenho Universal para a aprendizagem; Educação de Jovens e Adultos: desafios e práticas pedagógicas; Educação para a diversidade e inclusão: vencer barreira e impedimentos na perspectiva da pessoa com cegueira; Deficiência Intelectual.

Apontamos, com o mesmo peso e como dimensão central, os plurais contextos e lugares, os saberes e especificidades locais dos sujeitos tomados como referência. Pensar os sonhos, os desejos, as escolhas, as oportunidades, a cultura de um povo, no caso deste projeto A universidade que eu vivo é uma universidade que escuta e compartilha: vivenciando experiências de Políticas de Inclusão na América Latina, os sujeitos com deficiência como mais uma referência junto às demais referências de saberes e fazeres da academia. Pensar e vivenciar saberes e fazeres plurais entendendo-os da sua pertença, do seu ethos, de sua identidade aquecem práticas formadores. Acrescem as possibilidades de edificação de um ambiente inclusivo, de respeito aos princípios da diversidade humana, tanto internamente dentro da academia que se entende como possibilidades apreciativas no e com o outro.

\section{CONSIDERAÇÕES FINAIS}

Este projeto nasceu da experiência prática das ações da política de inclusão pensada pela Diretoria de Políticas e Ações Inclusivas (DAIN), da Universidade do Estado do Rio Grande do Norte, na América Latina e, para este estudo intitulado, A universidade queeu vivo é uma universidade que escuta e compartilha: vivenciando experiências dePolíticas 
de Inclusão na América Latina. Estabeleceu a propositura de uma temáticadiversificada voltada para o compartilhamento e troca de experiências, com vistas à implantação de uma rede interuniversitária para a criação e implementação de açõestendo como base a promoção do respeito aos princípios da diversidade humana e a efetivação de direitos para a cultura da paz.

Resultou na formação de uma rede de colaboração interuniversitária de formação docente, práticas e trajetórias educativas, no cotidiano de territórios como espaços de pluralidades culturais perseguindo o afloramento do (re)encantamento da arte das vivências educativas, das solidariedades que empurram os sujeitos para a reciprocidade, para as trocas, pelo gosto da busca pelo Outro, pela reconstrução das identidades, pelo entendimento da memória enquanto movimento, função e construção social e manutenção de vínculos. O envolvimento, a partilha e práticas de formação, nas regiões de fronteira entre os plurais espaços de aprendizado, nas diversas áreas de conhecimento no âmbito internacional, foram base para o reconhecimento dos diferentes sujeitos em sua diversidade, capazes de dialogar, de compartilhar vínculos ancorados em seus lugares de pertença, sobretudo a relevância deste projeto e seu desdobramento com a ação interuniversitária.

Destinou-se, com a mesma envergadura, à participação em eventos científicos na América Latina, com a repercussão em ações de mobilidade internacional com outros Programas e Centros de Pesquisa e Desenvolvimento Profissional e se fez levando ao desdobramento de assinatura de três intercâmbios de cooperação com Argentina, Peru, e Colômbia com a assessoria da Diretoria de Relações Internacionais da UERN para o compartilhamento de pesquisas e trocas de experiência.

\section{REFERÊNCIAS}

ALBERTI, V. Manual de história oral. 3. ed. Rio de Janeiro: FGV, 2005.

BOGDAN. R.; BIKLEN. S. Investigação qualitativa em educação: uma introdução à teoria e aos métodos. Portugal: Porto Editora, 1994.

BONDÍA, Jorge Larrosa. Notas sobre a experiência e o saber de experiência. Rev. Bras. Educ., Campinas, SP, n. 19, p. 20-28, abr. 2002. Disponível em: https://www. scielo.br/j/rbedu/a/Ycc5QDzZKcYVspCNspZVDxC/?lang=pt\&format=pdf. Acesso em: 31 maio 2017.

BRANDÃO, C. R. O que é Educação. 33. ed. São Paulo: Brasiliense, 1995.

CAILLÉ, A. Antropologia do Dom: o terceiro paradigma. Tradução de Ephraim Ferreira Alves. Petrópolis, RJ: Vozes, 2002.

FREIRE, P. Pedagogia do Oprimido. 46. ed. Rio de Janeiro: Paz e terra, 2005.

FREIRE, P. Pedagogia da esperança: um reencontro com a Pedagogia do Oprimido. Rio de Janeiro: Paz e Terra, 1997. Disponível em: http://www.dhnet.org.br/. Acesso em: 16abr. 1996.

JOSSO. M. C. Experiência de vida e formação. 2. ed. rev. e ampl. Natal, RN: EDUFRN; 
São Paulo: Paulus, 2010.

MAUSS, M. Antropologia. Tradução de Regina Lúcia Moraes Morel, Denise Maldi Meirelles e Ivonne Toscano. São Paulo: Ática, 1974.

MOROSINI, M. C.; USTÁRROZ, E. Impactos da internacionalização da educação superior na docência universitária: construindo a cidadania global por meio do currículo globalizado e das competências interculturais. Em Aberto, Brasília, v. 29, n.97, p. 3546, 2016.

MENEZES, Marilda. A; AIRES, Lídia M. Arnaud; SOUZA, Maria R. Construindo narrativas orais: interações sociais no trabalho de campo. Caderno de Campo, São Paulo, v. 12, n. 12, 2004.

TARDIF, M.; OULLETHE. Os saberes profissionais e de experiência docente. 1996. Resumo das ideias centrais do texto apresentado em congresso. 